\title{
Scaling-up Nanoparticle Beam Deposition for Green Synthesis of Advanced Materials ${ }^{\dagger}$
}

\author{
Richard E. Palmer 1,* \\ 1 Nanomaterials Lab, College of Engineering, Swansea University, UK \\ * Correspondence: r.e.palmer@swansea.ac.uk; \\ $\dagger$ Presented at Materials Chemistry and Physics (Materials Chemistry 2020) - International e-Conference
}

Received: 16.09.2020; Revised: 20.09.2020; Accepted: 24.09.2020; Published: 27.09.2020

\begin{abstract}
The deposition of size-controlled nanoparticles (atomic clusters) onto supports from the beam is a solvent-free, green route to small-scale manufacturing of functional nanomaterials. To translate the beautiful physics and chemistry of clusters into practical applications, e.g., coatings, catalysts, biochips, biomaterials, and photonic materials, significant scale-up of the rate of deposition is needed [1,2], while reducing the loss of material in the process (to say 1-10\%). For example, the deposition rate needed for industrial catalyst $R \& D$ is $10 \mathrm{mg} /$ hour of clusters, while for bespoke pharmaceutical manufacturing, $1-10 \mathrm{~g} /$ hour is required. In this talk, I will discuss both the fundamental aspects of deposited clusters at the atomic-scale - as revealed by aberration-corrected scanning transmission electron microscopy $[3,4]$ - and the status of efforts to meet the scale-up challenge, with emphasis on our "Matrix Assembly Cluster Source" (MACS) [5]. Some first practical demonstrations [6-10] of deposited clusters in heterogeneous and electrocatalysis will be presented, showing attractive activities and selectivities [1, 6-10], as an illustration of what might be done in fields as diverse as surface engineering, theranostics, photonics, and neuromorphic.
\end{abstract}

Keywords: nanoparticle; scaling-up; matrix assembly cluster source.

(C) 2020 by the authors. This article is an open-access article distributed under the terms and conditions of the Creative Commons Attribution (CC BY) license (https://creativecommons.org/licenses/by/4.0/).

\section{References}

1. $\quad$ Ellis, P.R.; Brown, C.M.; Bishop, P.T.; Yin, J.; Cooke, K.; Terry, W.D.; Liu, J.; Yin, F.; Palmer, R.E. The cluster beam route to model catalysts and beyond. Faraday Discussions 2016, 188, 39-56, https://doi.org/10.1039/C5FD00178A.

2. Palmer, R.E.; Cai, R.; Vernieres, J. Synthesis without Solvents: The Cluster (Nanoparticle) Beam Route to Catalysts and Sensors. Accounts of Chemical Research 2018, 51, 2296-2304, https://doi.org/10.1021/acs.accounts.8b00287.

3. Palmer, R.E.; Cao, L.; Yin, F. Note: Proof of principle of a new type of cluster beam source with potential for scale-up. Review of Scientific Instruments 2016, 87, https://doi.org/10.1063/1.4947229.

4. Foster, D.M.; Ferrando, R.; Palmer, R.E. Experimental determination of the energy difference between competing isomers of deposited, size-selected gold nanoclusters. Nature Communications 2018, 9, 1323, https://doi.org/10.1038/s41467-018-03794-9.

5. Foster, D.M.; Pavloudis, T.; Kioseoglou, J.; Palmer, R.E. Atomic-resolution imaging of surface and core melting in individual size-selected $\mathrm{Au}$ nanoclusters on carbon. Nature Communications 2019, 10, https://doi.org/10.1038/s41467-019-10713-z.

6. Cai, R.; Ellis, P.R.; Yin, J.; Liu, J.; Brown, C.M.; Griffin, R.; Chang, G.; Yang, D.; Ren, J.; Cooke, K.; Bishop, P.T.; Theis, W.; Palmer, R.E. Performance of Preformed Au/Cu Nanoclusters Deposited on $\mathrm{MgO}$ Powders in the Catalytic Reduction of 4-Nitrophenol in Solution. Small 2018, 14, https://doi.org/10.1002/smll.201703734.

7. Xu, J.; Murphy, S.; Xiong, D.; Cai, R.; Wei, X.-K.; Heggen, M.; Barborini, E.; Vinati, S.; Dunin-Borkowski, R.E.; Palmer, R.E.; Liu, L. Cluster Beam Deposition of Ultrafine Cobalt and Ruthenium Clusters for 
Efficient and Stable Oxygen Evolution Reaction. ACS Applied Energy Materials 2018, 1, 3013-3018, https://doi.org/10.1021/acsaem.8b00111.

8. Liao, T.-W.; Yadav, A.; Ferrari, P.; Niu, Y.; Wei, X.-K.; Vernieres, J.; Hu, K.-J.; Heggen, M.; DuninBorkowski, R.E.; Palmer, R.E.; Laasonen, K.; Grandjean, D.; Janssens, E.; Lievens, P. Composition-Tuned Pt-Skinned PtNi Bimetallic Clusters as Highly Efficient Methanol Dehydrogenation Catalysts. Chemistry of Materials 2019, 31, 10040-10048, https://doi.org/10.1021/acs.chemmater.9b02824.

9. Ayodele, O.B.; Cai, R.; Wang, J.; Ziouani, Y.; Liang, Z.; Spadaro, M.C.; Kovnir, K.; Arbiol, J.; Akola, J.; Palmer, R.E.; Kolen'ko, Y.V. Synergistic Computational-Experimental Discovery of Highly Selective PtCu Nanocluster Catalysts for Acetylene Semihydrogenation. ACS Catalysis 2020, 10, 451-457, https://doi.org/10.1021/acscatal.9b03539.

10. Cai, R.; Cao, L.; Griffin, R.; Chansai, S.; Hardacre, C.; Palmer, R.E. Scale-up of cluster beam deposition to the gram scale with the matrix assembly cluster source for heterogeneous catalysis (propylene combustion). AIP Advances 2020, 10, https://doi.org/10.1063/1.5142836.

\section{Funding}

EPSRC, EU, Leverhulme Trust, Welsh Government (IMPACT).

\section{Acknowledgments}

This research has no acknowledgment.

\section{Conflicts of Interest}

The authors declare no conflict of interest. 